Provided for non-commercial research and education use. Not for reproduction, distribution or commercial use.

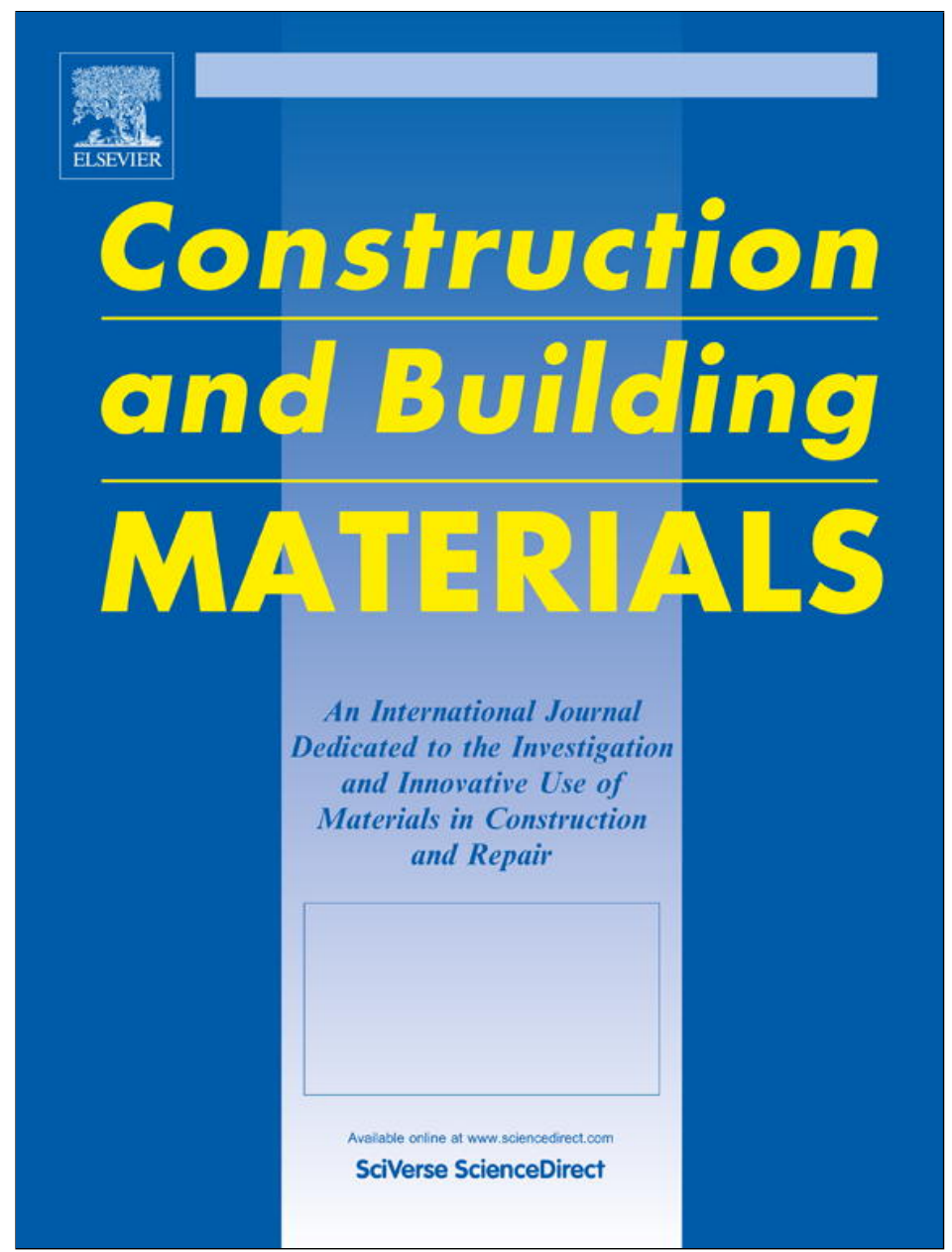

(This is a sample cover image for this issue. The actual cover is not yet available at this time.)

This article appeared in a journal published by Elsevier. The attached copy is furnished to the author for internal non-commercial research and education use, including for instruction at the authors institution and sharing with colleagues.

Other uses, including reproduction and distribution, or selling or licensing copies, or posting to personal, institutional or third party websites are prohibited.

In most cases authors are permitted to post their version of the article (e.g. in Word or Tex form) to their personal website or institutional repository. Authors requiring further information regarding Elsevier's archiving and manuscript policies are encouraged to visit:

http://www.elsevier.com/copyright 


\title{
Review
}

\section{Targeting HPC with the help of nanoparticles: An overview}

\author{
F. Pacheco-Torgal ${ }^{\mathrm{a}, *}$, S. Miraldo ${ }^{c}$, Y. Ding $^{\mathrm{b}}$, J.A. Labrincha ${ }^{\mathrm{c}}$ \\ ${ }^{a}$ University of Minho, C-TAC Research Centre, Guimarães, Portugal \\ ${ }^{\mathrm{b}}$ Dalian University of Technology, State Key Laboratory of Coastal and Offshore Engineering, Dalian, China \\ ${ }^{\mathrm{C}}$ University of Aveiro, CICECO, Aveiro, Portugal
}

\section{H I G H L I G H T S}

- Nano-particles has potential to develop HPC.

- Nano-silica is able to control calcium leaching.

- Colloidal dispersions are more effective to control calcium leaching.

\section{A R T I C L E I N F O}

\section{Article history:}

Received 5 June 2012

Received in revised form 2 August 2012

Accepted 14 August 2012

\section{Keywords:}

Portland cement

Nanoparticles

Calcium leaching

Concrete durability

HPC

\begin{abstract}
A B S T R A C T
According to the 2011 ERMCO statistics only a mere $11 \%$ of the ready-mixed concrete class production relates to the HPC target, furthermore, this percentage remains unchanged at least since the year 2001. This represents a strange option from the construction industry since HPC offers several advantages over normal-strength concrete, namely, high strength and high durability. Therefore, HPC allows for concrete structures with less steel reinforcement and a longer service life, both of which are crucial issues in the eco-efficiency of construction materials. Although nanotechnology is a very hot issue the fact is that investigations on the field of concrete with nanoparticles are rare (100 in 10,000 Scopus concrete related articles published in the last decade). Actually, it remains to be seen how this research area will contribute to concrete eco-efficiency. This paper summarizes current knowledge on the field of concrete containing nanoparticles. It includes the influence of nanoparticles on the mechanical properties of concrete and on its durability. It also includes calcium leaching control. Moreover, the problem of efficient dispersion of nanoparticles is analyzed.
\end{abstract}

\section{Contents}

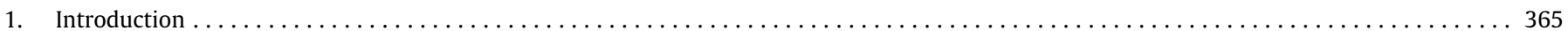

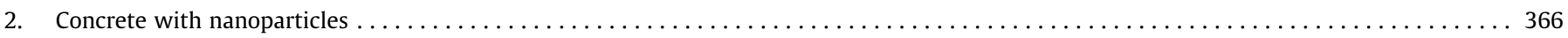

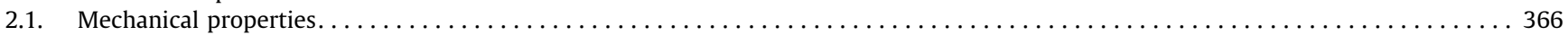

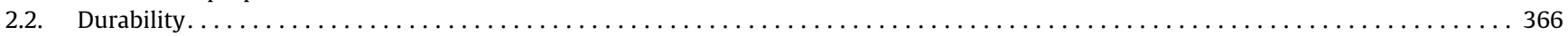

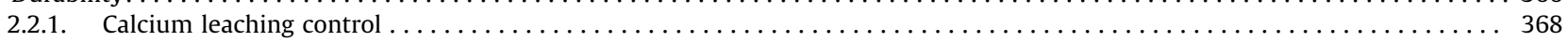

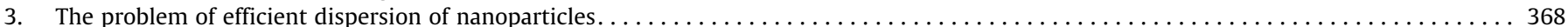

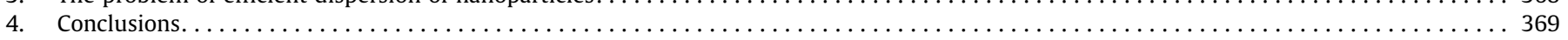

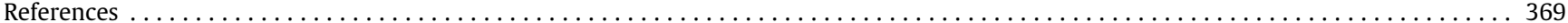

\section{Introduction}

Concrete is the most used construction material on Earth, its production reaching presently about $10 \mathrm{~km}^{3} / \mathrm{year}$ [1]. For

\footnotetext{
* Corresponding author. Tel.: +351 253 510200; fax: +351 253510213.

E-mail address: torgal@civil.uminho.pt (F. Pacheco-Torgal).
}

comparison, the amount of fired clay, timber, and steel used yearly in construction represent, respectively about $2,1.3 \mathrm{~km}^{3}$ and $0.1 \mathrm{~km}^{3}[2]$. The main binder of concrete, Portland cement, represents almost $80 \%$ of the total $\mathrm{CO}_{2}$ emissions of concrete which, in turn, are about $6-7 \%$ of the Planet's total $\mathrm{CO}_{2}$ emissions $[3,4]$. This is particularly serious in the current context of climate change and gets even worse. In fact, Portland cement demand is expected to 
increase almost 200\% by 2050 from 2010 levels reaching 6000 million tons/year. According to the ERMCO 2011 statistics [5], concrete ready-mixed class production lies essentially between $\mathrm{C} 25 /$ 30 and C30/37. Additionally, only $11 \%$ of the concrete production corresponds to the HPC strength class target. Since ERMCO 2001 statistics [6] showed a $10 \%$ figure for this type of concrete, this means that high strength concrete demand remains unchanged at least in the last decade. Normal-strength class concrete means less durable concrete structures which, in turn, require frequent maintenance and conservation operations or even its entire replacement (associated with the consumption of additional raw materials and energy). Besides many of the degraded concrete structures were built decades ago, when little attention was given to durability issues [7]. It is then no surprise to find out that worldwide concrete infrastructure rehabilitation costs are staggering. For example, in the USA about $27 \%$ of all highway bridges are in need of repair or replacement. Plus, the corrosion deterioration cost due to deicing and sea salt effects is estimated at over 150 billion dollars [8]. In the European Union nearly 84,000 reinforced and prestressed concrete bridges require maintenance, repair and strengthening resulting in an annual budget of $£ 215 \mathrm{M}$, being that this estimate does not include traffic management cost [9]. Beyond the durability problems originated by imperfect concrete placement and curing operations, the real issue of ordinary Portland cement concrete (OPC) durability is related to the intrinsic properties of that material. In effect, it presents a higher permeability which in turn, allows water and other aggressive elements to enter, leading to carbonation and chloride ion attack ultimately resulting in corrosion problems $[10,11]$. The importance of durability, in the context of construction and building materials eco-efficiency has been rightly put by Mora [12]. This author stated that increasing concrete durability from 50 to 500 years would mean a reduction of its environmental impact by a factor of 10 . It is also worth noticing that, according to Hegger et al. [13], the increase of compressive strength in concrete would mean a reduction in reinforced steel amount by as much as $50 \%$. These are crucial issues in the materials efficiency agenda $[14,15]$, highlighting the need for investigations that may allow for high mechanical strength and high durability concretes. Nanotechnology involves the study at microcospic scale $\left(1 \mathrm{~nm}=1 \times 10^{-9} \mathrm{~m}\right)$. Indeed some estimates predict that products and services related to nanotechnology could reach 1,000,000 million euro/year beyond 2015 [16].

The use of nanoparticles to increase the strength and durability of cimentitious composites was already predicted by the report RILEM TC 197-NCM, "Nanotechnology in construction materials" [17], to be a research area with high nanotech potential. And in fact, since then, several dozen SCI papers have been published on that field. However, the majority of those publications where authored by materials science investigators, these show a high concern on the materials performance but with a weak focus on civil engineering short term commercial applications. For instance the "bottom-up" multiscale modeling approach [18], could be an excellent strategy that "has been spectacularly successful in fields ranging from metallurgy to medicine" [19] but, unfortunately, relies on tools that "that require years of training and considerable computational expense to operate", both of which not traditionally associated with the construction industry. The importance of the present review relates to the need to redirect future investigations on this field to a precise target that could serve a clear civil engineering short term goal such as HPC production.

\section{Concrete with nanoparticles}

The production of nanoparticles can be obtained either through a high milling energy [20] or by chemical synthesis [21].

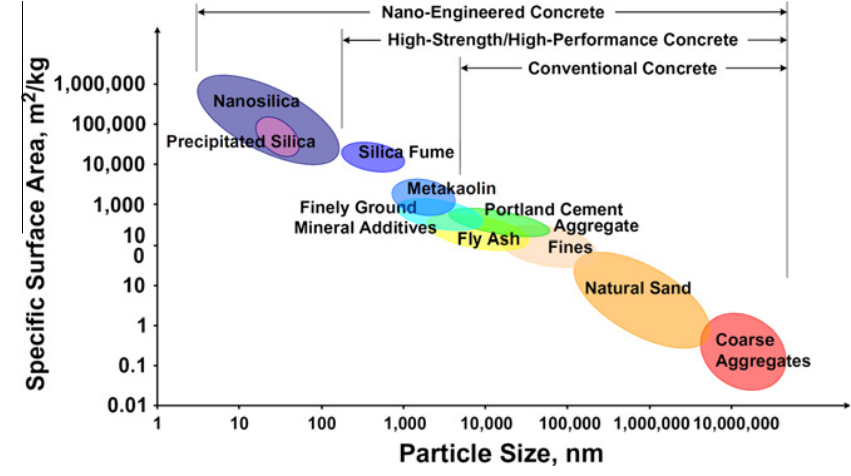

Fig. 1. Particle size and specific surface area related to concrete materials [22].

Nanoparticles have a high surface area to volume ratio (Fig. 1) providing high chemical high reactivity. Most investigations use nanosilica (nano- $\mathrm{SiO}_{2}$ ), and nano-titanium oxide $\left(\right.$ nano- $\mathrm{TiO}_{2}$ ) while a few use nano- $\mathrm{Fe}_{2} \mathrm{O}_{3}[22]$.

\subsection{Mechanical properties}

Porro et al. [23] mentioned that the use of nano-silica particles increases the compression strength of cement pastes. The same authors state that this phenomenon is not due to the pozzolanic reaction, because calcium hydroxide consumption was very low but, instead, to the increase of silica compounds that, in turn, contributes to a denser microstructure. According to Lin et al. [24], the use of nanosilica on sludge/fly ash mortars, compensates the negative effects associated to sludge incorporation in terms of setting time and initial strength. Sobolev et al. [25] reported that nanosilica addition led to an increase of strength by $15-20 \%$. Other authors $[26,27]$ believe that nanosilica leads to an increase of the $\mathrm{C}-\mathrm{S}-\mathrm{H}$ chain dimension and also $\mathrm{C}-\mathrm{S}-\mathrm{H}$ stiffness. Moreover, Nasibulin et al. [28] reported an increase in strength by two times. Chaipanich et al. [29] mentioned that $1 \%$ of carbon nanotubes (by binder mass) can compensate the strength reduction associated with the replacement of $20 \%$ fly ash. Konsta-Gdoutos et al. [30] also studied the effect of carbon nanotubes on cement pastes $(0.08 \%$ by binder mass) observing an increase in strength. Other authors [31] used $\mathrm{ZnO}_{2}$ nano-particles with the average particle size of $15 \mathrm{~nm}$ reporting an improvement in the flexural strength of self-compacting concrete up to $4 \mathrm{wt}$.\%. Increasing nano-particles content caused a reduction in the flexural strength because of unsuitable dispersion of nanoparticles in the concrete matrix. Givi et al. [32] studied the effects of different particle size of nano- $\mathrm{SiO}_{2}(15$ and $80 \mathrm{~nm}$ ) reporting that the optimal replacement level of nano- $\mathrm{SiO}_{2}$ particles were gained at $1.0 \%$ and $1.5 \%$, respectively. Basically the effect of nanoparticles addition is threefold:

1. Since the average diameter of $\mathrm{C}-\mathrm{S}-\mathrm{H}$ gel is approximately $10 \mathrm{~nm}$ the nano-particles can fill the voids of the CHS structure leading to a denser concrete.

2. The nano-particles act as nucleation centers, contributing to the development of the hydration of Portland cement.

3. Nano-particles react with $\mathrm{Ca}(\mathrm{OH})_{2}$ crystals producing $\mathrm{C}-\mathrm{S}-\mathrm{H}$ gel. Besides the nano-particles act as kernels in the cement paste which makes the size of $\mathrm{Ca}(\mathrm{OH})_{2}$ crystal smaller.

\subsection{Durability}

Investigations carried out by Ji [33] showed that concrete containing nano-silica particles show lower water permeability. The explanation has to do with the reduction of the amount of $\mathrm{Ca}(\mathrm{OH})_{2}$ 
leading to a denser ITZ. The reduction of the chloride ion permeability when using $1 \%$ of nanoparticles per cement mass was reported by others [34]. Other authors [35] showed that nanoparticles are more favorable to the abrasion resistance of concrete than PP fibers. They also added that the abrasion resistance of concrete containing nano-particles decreases with nano-particles and that the abrasion resistance of concrete containing nano- $\mathrm{TiO}_{2}$ is better than that containing the same amount of nano- $\mathrm{SiO}_{2}$. Chen and Lin [36] used nano-silica particles to improve the performance of sludge/clay mixtures for tile production. The results show that nanoparticles improved the reduction of water absorption and led to an increase of abrasion and impact strength. A reduction in the water absorption was reported by others [37]. Ozyildirim and Zegetosky [38] used $4 \%$ of nano- $\mathrm{Fe}_{2} \mathrm{O}_{3}$ per cement mass also reporting a reduction in the concrete permeability. A reduction on concrete permeability was also reported for concrete with 45\% Portland cement replacement by GGBFS containing $4 \%$ of nano- $\mathrm{TiO}_{2}$ per cement mass [39]. Shekari and Razzaghi [40] compared the mechanical performance and the durability of concretes containing $1.5 \%$ of different nanoparticles (nano- $\mathrm{ZrO}_{2}$, nano- $\mathrm{TiO}_{2}$,
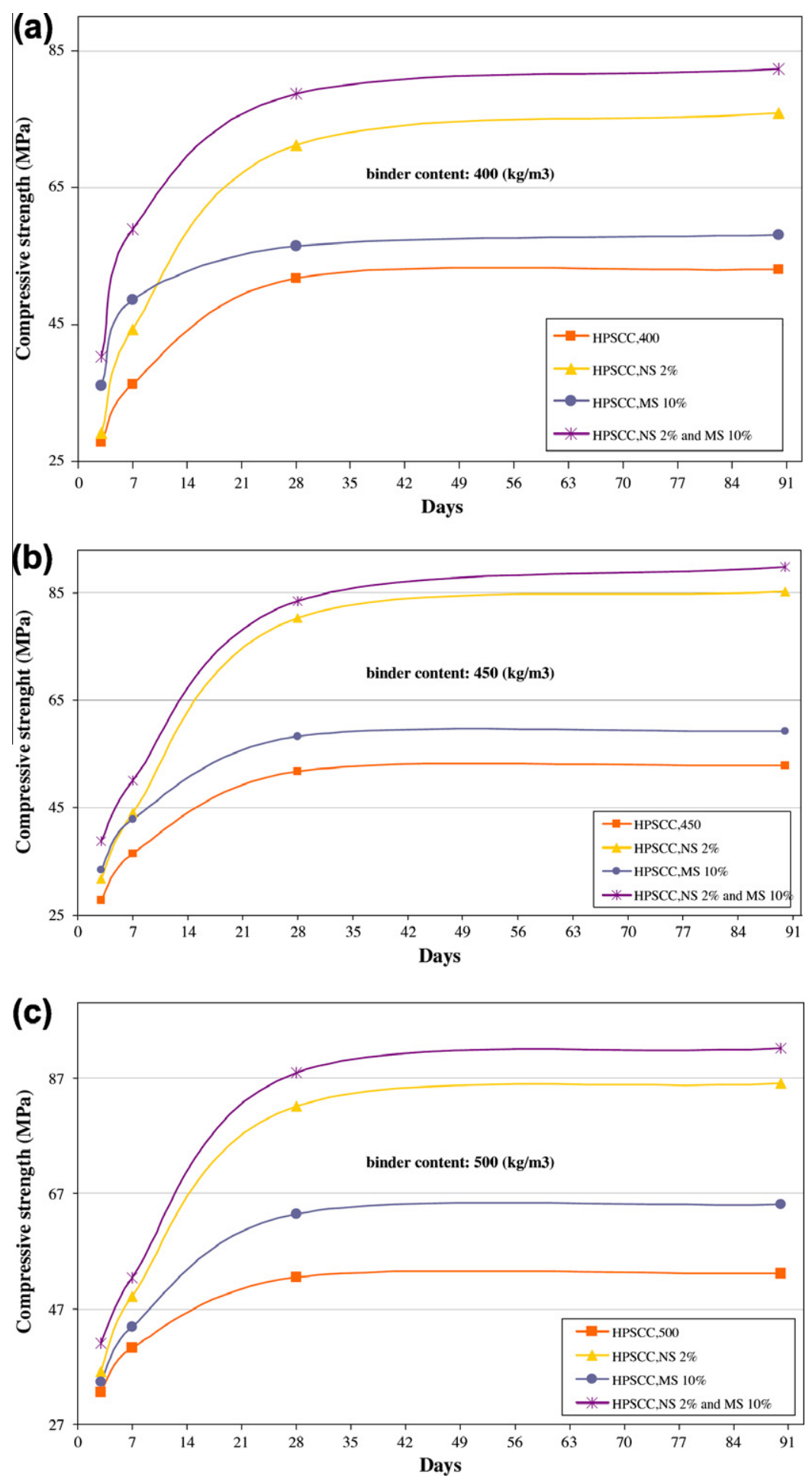

Fig. 2. Compressive strength of HPSCC samples with binder contents of (a) 400, (b) 450 and (c) 500 [41]. 


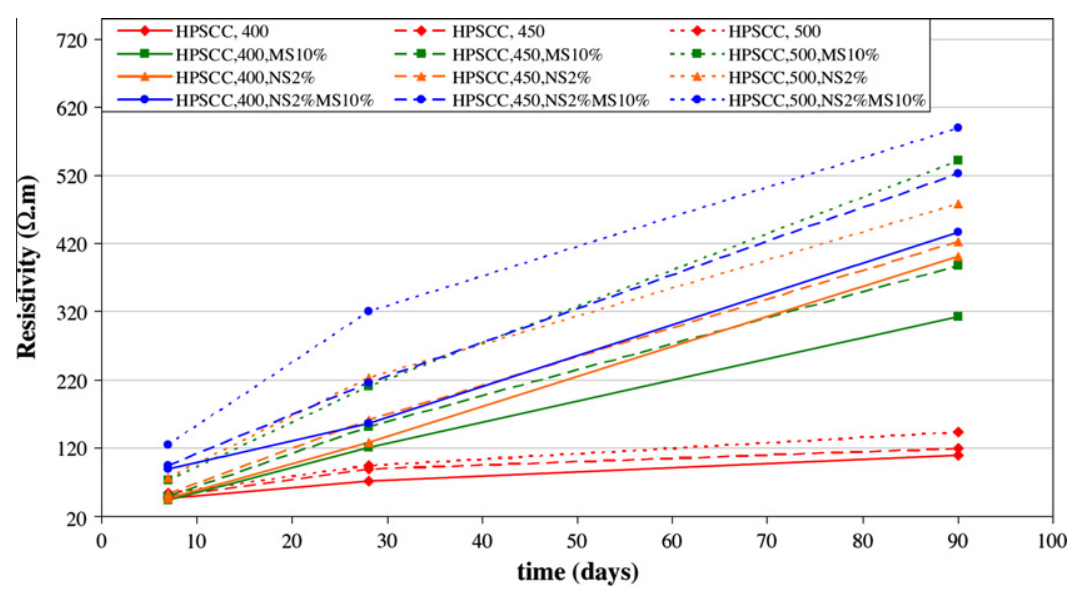

Fig. 3. Resistivity versus time for different mixtures [41].

nano- $\mathrm{Al}_{2} \mathrm{O}_{3}$, nano- $-\mathrm{Fe}_{3} \mathrm{O}_{4}$ ) concluding that the nano- $\mathrm{Al}_{2} \mathrm{O}_{3}$ is the most effective. Nevertheless, no explanation was put forward to explain this fact. Other authors [41] study concrete performance with replacement of Portland cement by up to $2 \%$ nano- $\mathrm{Al}_{2} \mathrm{O}_{3}$, with average particle size of $15 \mathrm{~nm}$, reporting that the optimum level of nano- $\mathrm{Al}_{2} \mathrm{O}_{3}$ particles content was achieved at $1.0 \%$. Jalal et al. [42] showed that concretes using $2 \% \mathrm{SiO}_{2}$ nanoparticles underperform when compared to concretes with $2 \% \mathrm{SiO}_{2}$ nanoparticles plus $10 \%$ micro silica, this composition has in fact, an enhanced effect on mechanical strength (Fig. 2) as well as on durability, which is assessed by water absorption, capillary water absorption, $\mathrm{Cl}$ ion percentage and resistivity (Fig. 3). According to Zhang and Li [43], the pore structure of concretes containing nano- $\mathrm{TiO}_{2}$ is finer than that of concretes containing the same amount of nano- $\mathrm{SiO}_{2}$. The resistance to chloride penetration of concretes containing nano- $\mathrm{TiO}_{2}$ is higher than that of concretes containing the same amount of nano- $\mathrm{SiO}_{2}$. The explanation for that relies on the fact that the particle diameter of nano- $\mathrm{SiO}_{2}$ is smaller than that of nano- $\mathrm{TiO}_{2}$, and the specific surface area of nano- $\mathrm{SiO}_{2}$ is much larger than that of nano- $-\mathrm{TiO}_{2}$, so that the water demand of concrete containing nano- $\mathrm{SiO}_{2}$ is more than that of concrete containing the same amount of nano- $\mathrm{TiO}_{2}$. The referred authors also reported that the pore structure refinement increases with the content of nano-particles $(5<3<1 \%)$ and also that the chloride penetration decreases with the content of nano-particles $(5<3<1 \%)$. These results partially confirm the ones already obtained by Li et al. [35]. In their view with the increasing content of nano-particles, the refinement of pore structure of concrete is weakening. This can be attributed to that the distance between nano-particles decreases with the increasing content of nano-particles, and $\mathrm{Ca}(\mathrm{OH})_{2}$ crystal cannot grow up enough due to limited space and the crystal quantity is decreased, which causes the ratio of crystal to $\mathrm{C}-\mathrm{S}-\mathrm{H}$ gel to become small and the shrinkage and creep of cement matrix to increase, thus the pore structure of cement matrix is coarser relatively [43].

\subsubsection{Calcium leaching control}

High durability concrete encompasses the reduction of calcium leaching. This degradation process consists in the progressive dissolution of the cement paste by the migration of calcium atoms to the aggressive solution. The different cement paste phases have different degradation rates. While Portlandite dissolves completely in the aggressive solution, the CSH gel solely undergoes a slight porosity increase [44-47]. Calcium leaching is responsible for an increase in concrete porosity and, consequently, increased permeability; this allows water and other aggressive elements to enter concrete, leading to carbonation and corrosion problems. Gaitero et al. [48] studied the influence of silica nano-particles on the cal-
Table 1

Main physicochemical properties of the commercial additions used as stated by the manufacturer [48].

\begin{tabular}{ccclll}
\hline Name & $\begin{array}{l}\text { Particle size } \\
(\mathrm{nm})\end{array}$ & $\mathrm{pH}$ & $\begin{array}{l}\text { Stabilizing } \\
\text { agent }\end{array}$ & $\begin{array}{l}\mathrm{SiO}_{2} \text { content } \\
\text { (wt.\%) }\end{array}$ & Presentation \\
\hline CS1 & 30 & 10 & $\mathrm{Na}_{2} \mathrm{O}$ & 45 & Colloid \\
CS2 & 20 & 10 & $\mathrm{Na}_{2} \mathrm{O}$ & 20 & Colloid \\
CS3 & 120 & 9.5 & $\mathrm{NH}_{3}$ & 40 & Colloid \\
ADS & 1400 & - & - & 95 & Powder \\
\hline
\end{tabular}

All the colloids were dispersed in water being the amount of the stabilizing agents $<0.1 \mathrm{wt} . \%$.

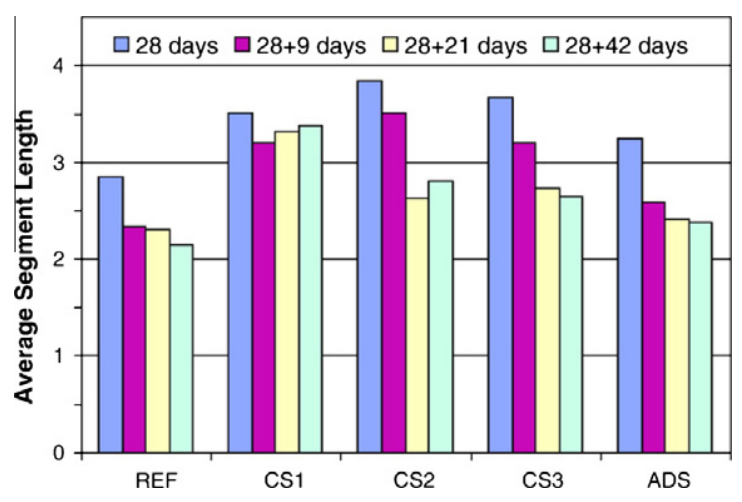

Fig. 4. Evolution of the average segment length. The results were obtained from the relative areas of the ${ }^{29} \mathrm{Si}$ MAS-NMR spectra [48].

cium leaching reduction. Mixtures containing 6\% (by weight of cement) of four different types of commercial silica nanoparticles (Table 1) were used. Fig. 4 shows that the addition of silica nanoparticles to the cement paste favours the growth of the silicate chains, increasing their average length and longer chains correspond to more stable $\mathrm{C}-\mathrm{S}-\mathrm{H}$. The authors concluded that the addition of nano-silica to cement-based materials can control C-S-H degradation induced by Ca-leaching. However, the beneficial effects depend on the presentation of the nanoparticles. Colloidal dispersions were much more effective reducing the effects of the degradation than the dry ones.

\section{The problem of efficient dispersion of nanoparticles}

The most significant issue for nanoparticles is that of effective dispersion. Veras-Agulho et al. [49] states that the use of 

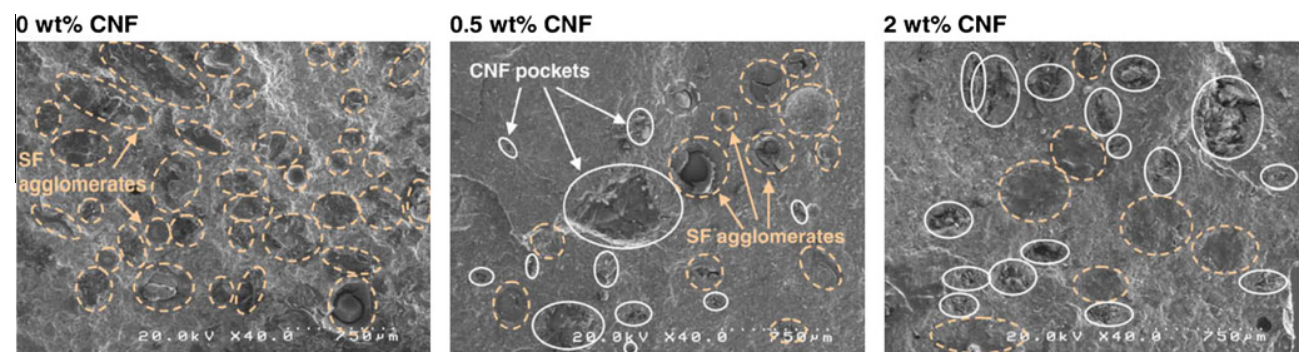

Fig. 5. Scanning electron micrographs of the fracture surface of hybrid CNF/SF cement composites, revealing the presence and distribution of SF agglomerates and CNF pockets at a magnification of $40 \times$

nanoparticles is responsible for a higher hydration degree of cementitious compounds as long as higher nanoparticles dispersion can be achieved. Other authors [32] mentioned that to contribute to a proper dispersion of nano- $\mathrm{SiO}_{2}$ particles, they were stirred with some of the mixing water at high speed $(120 \mathrm{rpm})$ for $1 \mathrm{~min}$ and then added to the mixture. Zhang and Li [43] used a water-reducing agent (UNF-5, one kind of b-naphthalene sulfonic acid and formaldehyde condensates) to aid the dispersion of nanoparticles in cement paste and achieve good workability of concrete. Also, a defoamer (tributyl phosphate) was used to decrease the amount of air bubbles. To prepare the concrete containing nanoparticles, a water-reducing agent was firstly mixed into water in a mortar mixer, then, nano-particles were added and stirred at a high speed for $5 \mathrm{~min}$. Later, the defoamer was added as stirring. After this, the cement, sand and coarse aggregate were mixed at a low speed for $2 \mathrm{~min}$ in a concrete centrifugal blender, and then the mixture of water, water-reducing agent, nano-particles and defoamer was slowly poured in and stirred at low speed for another 2 min to achieve good workability. The dispersion problem also occurs when carbon nanotubes/carbon nanofibers are used due to their high strong Van der Waals self-attraction [50]. Sanchez and Ince [51] confirm that the Van der Waals forces held the carbon nanofibers together as clumps (Fig. 5). These authors found that silica fume facilitated carbon nanofibers dispersion due to its small particle size when compared to that of anhydrous cement particles (ca. 100 times smaller).

\section{Conclusions}

The literature review about nanoparticles contribution for HPC shows that:

(a) Nanoparticles allows for a dramatic increase in the mechanical strength of cementitious composites. The mechanisms are as follows:

1. They can fill the voids of the CHS structure leading to a denser concrete.

2. They act as nucleation centers, contributing to the development of the hydration of Portland cement.

3. They react with $\mathrm{Ca}(\mathrm{OH})_{2}$ crystals producing $\mathrm{C}-\mathrm{S}-\mathrm{H}$ gel. Besides the nano-particles act as kernels in the cement paste which makes the size of $\mathrm{Ca}(\mathrm{OH})_{2}$ crystal smaller.

(b) The optimal percentage of nanoparticles depends on their type and also on their average dimension.

(c) Further investigations are needed in order to find out which nano-particles are most effective for enhanced concrete durability.

(d) Nano-silica seems to be able to control calcium leaching. Colloidal dispersions were much more effective reducing the effects of the degradation than the dry ones.

\section{References}

[1] Gartner E, Macphee D. A physico-chemical basis for novel cementitious binders. Cem Concr Res 2011;41:736-49.

[2] Flatt R, Roussel R, Cheeseman CR. Concrete: an eco-material that needs to be improved. J Eur Ceram Soc 2012;32;2787-98.

[3] Shi C, Fernández Jiménez A, Palomo A. New cements for the 21st century: the pursuit of an alternative to Portland cement. Cem Concr Res 2011;41: 750-63.

[4] Pacheco-Torgal F, Jalali S, Labrincha J, John VM. Eco-efficient concr. Cambridge (UK): WoodHead Publishing Ltd.; in press.

[5] ERMCO. Statistics of the year 2010. Boulevard du Souverain 68, B-1170 Brussels, Belgium; 2011.

[6] ERMCO. Statistics of the year 2000. Boulevard du Souverain 68, B-1170 Brussels, Belgium; 2001.

[7] Hollaway LC. Key issues in the use of fibre reinforced polymer (FRP) composites in the rehabilitation and retrofitting of concrete structure. In: Karbhari VM, Lee LS, editors. Service life estimation and extension of civil engineering structures. Abington Hall (Cambridge): Woodhead Publishing Ltd.; 2011.

[8] Davalos JF. Advanced materials for civil infrastructure rehabilitation and protection. Seminar at The Citty College of New York, New York; 2012.

[9] Yan L, Chouw N. Behavior and analytical modeling of natural flax fibre reinforced polymer tube confined plain concrete and coir fibre reinforced concrete. J Compos Mater; in press.

[10] Bentur A, Mitchell D. Material performance lessons. Cem Concr Res 2008;38:259-72.

[11] Glasser $\mathrm{F}$ et al. Durability of concrete. degradation phenomena involving detrimental chemical reactions. Cem Concr Res 2008;38:226-46.

[12] Mora E. Life cycle, sustainability and the transcendent quality of building materials. Build Environ 2007;42:1329-34.

[13] Hegger J, Nitsch A, Burkhardt J. Hchleistungbeton im Fertigteilbau. Betonwerk Fertigteil - Tech 1997;2:81-90.

[14] Pacheco-Torgal F, Jalali S. Eco-efficient construction and building materials. London (UK): Springer Verlag; 2011.

[15] Allwood J, Ashby M, Gutowski T, Worrell E. Material efficiency: a white paper. Resour Conserv Recycl 2011;55:362-81.

[16] Pacheco-Torgal F, Jalali S. Nanotechnology: advantages and drawbacks in the field of building materials. Constr Build Mater 2011;25:582-90.

[17] Zhu W, Bartos P, Porro A. Application of nanotechnology in construction. Summary of a state-of-the-art report. RILEM TC 197-NCM. Mater Struct 2004;37:649-58.

[18] Pellenq R, Kushima A, Shahsavar R, Vliet K, Buehler M, Yip S, et al. In: Bazant Z, editor. A realistic molecular model of cement hydrates. Northwestern University, PNAS; 2009.

[19] Jennings H, Bullard J. From electrons to infrastructure: engineering concrete from the bottom up. Cem Concr Res 2011;41:727-35.

[20] Sobolev K, Ferrada-Gutierrez M. How nanotechnology can change the concrete world: Part 2. Am Ceram Soc Bull 2005;84:16-9.

[21] Lee S, Kriven W. Synthesis and hydration study of Portland cement components prepared by organic steric entrapment method. Mater Struct 2005;38:87-92.

[22] Sanchez F, Sobolev K. Nanotechnology in concrete - a review. Constr Build Mater 2010;24:2060-71.

[23] Porro A, Dolado J, Campillo I, Erkizia E, De Miguel Y, De Ybarra Y, Ayuela A. Effects of nanosilica additions on cement pastes. In: Proc international conference on applications of nanotechnology in concrete design; 2005. p. $87-96$.

[24] Lin D, Lin K, Chang W, Luo H, Cai M. Improvements of nano-SiO ${ }_{2}$ on sludge/fly ash mortar. Waste Manage 2008;28:1081-7.

[25] Sobolev K, Flores I, Hermosillo R, Torres-Martinez L. Nanomaterials and nanotechnology for high-performance cement composites, vol. 254. American Concrete Institute, ACI Special Publication; 2008. p. 93-120.

[26] Gaitero J. Multi-scale study of the fibre matrix interface and calcium leaching in high performance concrete. Ph.D thesis. Centre for nanomaterials applications in construction of Labein-Tecnalia. Spain; 2008. 
[27] Gaitero J, Zhu W, Campillo I. Multi-scale study of calcium leaching in cement pastes with silica nanoparticles. Nanotechnology in construction, vol. 3. Berlin Heidelberg: Springer; 2009.

[28] Nasibulin A, Shandakov S, Nasibulina L, Cwirzen A, Mudimela P, HabermehlCwirzen $\mathrm{K}$, et al. A novel cement-based hybrid material. New J Phys 2009:023013.

[29] Chaipanich A, Nochaya T, Wongkeo W, Torkittikul P. Compressive strength and microstructure of carbon nanotubes-fly ash cement composites. Mater Sci Eng 2010;A527:1063-76.

[30] Konsta-Gdoutos M, Metaxa Z, Shah S. Highly dispersed carbon nanotube reinforced cement based materials. Cem Concr Res 2010;40:1052-9.

[31] Nazari A, Riahi S. The effects of zinc dioxide nanoparticles on flexural strength of self-compacting concrete. Composites: Part B 2011;42:167-75.

[32] Givi A, Rashid S, Aziz F, Salleh M. Experimental investigation of the size effects of $\mathrm{SiO}_{2}$ nano-particles on the mechanical properties of binary blended concrete. Composites: Part B 2010;41:673-7.

[33] Ji T. Preliminary study on the water permeability and microstructure of concrete incorporating nano-SiO ${ }_{2}$. Cem Concr Res 2005;35(2005):1943-7.

[34] He X, Shi X. Chloride permeability and microstructure of Portland cement mortars incorporating nanomaterials. Transportation Research Record: Journa of the Transportation Research Board, No. 2070. Transportation Research Board of the National Academies. Washington, DC; 2008. p. 13-21.

[35] Li H, Zhang M-H, Ou J-P. Abrasion resistance of concrete containing nanoparticles for pavement. Wear 2006;260:1262-6.

[36] Chen L, Lin D. Applications of sewage sludge ash and nano- $\mathrm{SiO}_{2}$ to manufacture tile as construction material. Constr Build Mater 2009;23: 3312-20.

[37] Givi A, Rashid S, Aziz F, Salleh M. The effects of lime solution on the properties of $\mathrm{SiO}_{2}$ nanoparticles binary blended concrete. Composites: Part B 2011;42:562-9.

[38] Ozyildirim C, Zegetosky C. Laboratory investigation of nanomaterials to improve the permeability and strength of concrete. Virginia Transportation Research Council. Final Report VTRC 10-R18; 2010.

[39] Khoshakhlagh et al. Effects of $\mathrm{Fe}_{3} \mathrm{O}_{3}$ nanoparticles on water permeability and strength assessments of high strength self-compacting concrete. J Mater Sci Technol 2012;28:73-82.
[40] Shekari A, Razzaghi M. Influence of nanoparticles on durability and mechanical properties of high performance concrete. Proc Eng 2011:14:3036-41.

[41] Nazari A, Riahi S. $\mathrm{Al}_{2} \mathrm{O}_{3}$ nanoparticles in concrete and different curing media. Energy Build 2011;43:1480-8.

[42] Jalal M, Mansouri E, Sharifipour M, Pouladkhan A. Mechanical, rheological, durability and microstructural properties of high performance selfcompacting concrete containing $\mathrm{SiO}_{2}$ micro and nanoparticles. Mater Des 2012;34:389-400.

[43] Zhang M-H, Li H. Pore structure and chloride permeability of concrete containing nano-particles for pavement. Constr Build Mater 2011;25:608-16.

[44] Carde C, Franqois R, Torrenti J. Leaching of both calcium hydroxide and C-S-H from cement paste: modeling the mechanical behaviour. Cem Concr Res 1996;26:1257-68.

[45] Kamali S, Gerard B, Moranville M. Modeling the leaching kinetics of cement based materials-influence of materials and environment. Cem Concr Compos 2003;25:451-8.

[46] Haga K, Sutou S, Hironaga M, Tanaka S, Nagasaki S. Effects of porosity on leaching of Ca from hardened ordinary Portland cement paste. Cem Concr Res 2005;35:1764-75.

[47] Gaitero J, Dolado J, Neuen C, Heber F, Koenders E. Computational 3D simulation of calcium leaching in cement matrices. INS Preprint No. 1203. Institut fur numerische simulation, Rheinische Friedrich-Wilhelms-Universitat Bonn; 2012.

[48] Gaitero J, Campillo L, Guerrero A. Reduction of the calcium leaching rate of cement paste by addition of silica nanoparticles. Cem Concr Res 2008;38:1112-8.

[49] Veras-Agullo J, Chozas-Ligero V, Portillo-Rico D, Garcia-Casas M, GutierrezMartinez A, Mieres-Royo J, et al. Mortar and concrete reinforced with nanomaterials. Nanotechnology in construction, vol. 3. Berlin Heidelberg: Springer; 2009.

[50] Xie X-L, Mai Y-W, Zhou X-P. Dispersion and alignment of carbon nanotubes in polymer matrix: a review. Mater Sci Eng R 2005;49:89-112.

[51] Sanchez F, Ince C. Microstructure and macroscopic properties of hybrid carbon nanofiber/silica fume cement composites. Compos Sci Technol 2009;69:1310-8. 